\section{Idiopathic polypoidal choroidal vasculopathy: a disease with diverse clinical spectrum and systemic associations}

PECK-LIN LIP, MONIQUE W. HOPE-ROSS, JONATHAN M. GIBSON

\begin{abstract}
Purpose To report the clinical findings, angiographic results, clinical course, response to laser photocoagulation and systemic associations in a group of patients with idiopathic polypoidal choroidal vasculopathy (IPCV).
\end{abstract}

Methods All patients with IPCV attending the macular clinic underwent a complete ocular examination, and fluorescein and indocyanine green angiography. In addition, a systemic examination including blood pressure, full blood count, plasma viscosity and coagulation status of patients was carried out.

Results We present a series of 5 patients $(7$ eyes) with clinical and angiographic evidence of IPCV with follow-up of 3-6 years. We report diverse demographic and clinical manifestations. One patient had polypoidal lesions found at the peripheral retina (anterior to equator) of both eyes. Three patients were treated with laser photocoagulation and achieved stable vision; 2 patients who had no laser treatment experienced deteriorated vision, one of whom had a vitrectomy. One patient was hypertensive, 2 patients were found to have raised plasma viscosity, and 1 patient had thrombocytopenia.

Conclusions The clinical spectrum of IPCV is wider than previously documented. It is a distinct clinical entity which should be differentiated from other forms of haemorrhagic and exudative maculopathy. The availability of indocyanine green angiography has allowed increased recognition of these cases. Early selective laser treatment on lesions affecting maculae could stabilise the disease. Its association with systemic cardiovascular disease and blood disorder may predispose to the recurrence of haemorrhagic events in this entity.

Key words Blood abnormality, Hypertension, Idiopathic polypoidal choroidal vasculopathy, Laser, Systemic associations
Idiopathic polypoidal choroidal vasculopathy (IPCV) is a unique disease of the choroidal circulation which has been increasingly recognised as a clinical entity separate from agerelated macular degeneration in recent years. Its clinical features are not unlike those of agerelated maculopathy but it is also characterised by frequent and recurrent haemorrhagic detachments of both the retinal pigment epithelium and neurosensory retina. The leakage is thought to be from an often visible cluster of peculiar orange choroidal vascular projections of unknown aetiology, although they are thought to be aneurysmal bulges of the inner choroidal vascular network. ${ }^{1,2}$ These lesions are predominantly found in the peripapillary area. ${ }^{3}$ Visual loss is secondary to recurrent vitreous haemorrhage or foveal involvement. This series presents a case with peripheral retina involvement (anterior to the equator) as a wider clinical spectrum.

The disease was previously described to be associated with primarily Afro-Caribbean hypertensive women. ${ }^{1-5}$ Some systemic associations and blood disorders, previously unreported in literature, are also reported in our series.

\section{Methods}

All patients with IPCV attending the macular clinic were evaluated. A complete clinical ocular examination, and fluorescein and indocyanine green angiography were performed. In addition, a systemic examination including blood pressure, full blood count, plasma viscosity and coagulation status of patients was carried out. Argon green laser photocoagulation was performed when indicated and follow-up ranged from 3 to 6 years.

\section{Results}

We present a series of 5 patients ( 7 eyes) with clinical and angiographic evidence of IPCV with different courses of clinical management. We

\section{P.L. Lip \\ M.W. Hope-Ross \\ J.M. Gibson \\ Birmingham and Midland Eye Centre \\ Birmingham, UK}

Mrs Peck-Lin Lip Birmingham and Midland Eye Centre

City Hospital NHS Trust

Dudley Road

Birmingham B18 7QH, UK

Tel: +44 (0)121554 3801

Fax: $+44(0) 1215544083$

e-mail:

g.y.h.lip.@bham.ac.uk

Presented as a poster at the Annual Conference of the Royal College of Ophthalmologists, 1998

Received: 13 December 1999 Accepted in revised form:

17 February 2000 
Table 1. Demographic characteristics, clinical manifestations and management of IPCV in this series

\begin{tabular}{|c|c|c|c|c|c|c|c|c|c|c|c|c|}
\hline \multirow{2}{*}{$\begin{array}{l}\text { Patient } \\
\text { no. }\end{array}$} & \multirow{2}{*}{$\begin{array}{c}\text { Age } \\
\text { (years) }\end{array}$} & \multirow[b]{2}{*}{ Sex } & \multirow[b]{2}{*}{ Race } & \multirow{2}{*}{$\begin{array}{l}\text { Hypertension } \\
(\mathrm{BP}, \mathrm{mmHg})\end{array}$} & \multirow{2}{*}{$\begin{array}{l}\text { Past } \\
\text { medical } \\
\text { history }\end{array}$} & \multirow{2}{*}{$\begin{array}{l}\text { Blood } \\
\text { abnormality }\end{array}$} & \multirow[b]{2}{*}{ Eyes } & \multirow{2}{*}{$\begin{array}{l}\text { Clinical } \\
\text { findings }\end{array}$} & \multicolumn{2}{|c|}{ Visual acuity } & \multirow[b]{2}{*}{ Treatment } & \multirow{2}{*}{$\begin{array}{c}\text { Follow-up } \\
\text { (years) }\end{array}$} \\
\hline & & & & & & & & & Initial & Final & & \\
\hline \multirow[t]{2}{*}{1} & 58 & M & AC & $\begin{array}{l}\text { No } \\
(130 / 70)\end{array}$ & Syphilis & $\mathrm{PV}=1.78$ & RE involved & $\begin{array}{l}\text { VH, Hg PED } \\
\text { (mid-peripheral } \\
\text { macula) }\end{array}$ & $6 / 36$ & PL & Vitrectomy & 6 \\
\hline & & & & & & & LE normal & No drusen & $6 / 5$ & $6 / 5$ & - & \\
\hline \multirow[t]{2}{*}{2} & 82 & M & W & $\begin{array}{l}\text { No } \\
(130 / 60)\end{array}$ & MI & $\begin{array}{l}\mathrm{PV}=1.74 \\
\text { Idiopathic } \\
\text { thrombocyto- } \\
\text { penia }\end{array}$ & RE involved & $\begin{array}{l}\text { Hg PEDs } \\
\text { (peripheral) }\end{array}$ & $6 / 12$ & $2 / 60$ & - & 5 \\
\hline & & & & & & & LE involved & $\begin{array}{l}\text { VH, Hg PED } \\
\text { (peripheral) }\end{array}$ & $6 / 60$ & $6 / 60$ & - & \\
\hline \multirow[t]{2}{*}{3} & 63 & $\mathrm{~F}$ & $A C$ & $\begin{array}{l}\text { Yes } \\
(170 / 100)\end{array}$ & Nil & $\uparrow \mathrm{PV}=1.94$ & RE involved & $\begin{array}{l}\text { VH, Hg PED } \\
\text { (peripapillary) }\end{array}$ & $6 / 9$ & $6 / 9$ & Laser $(\times 3)$ & 3 \\
\hline & & & & & & & LE involved & Old VH & $\mathrm{HM}$ & $\mathrm{HM}$ & - & \\
\hline \multirow[t]{2}{*}{4} & 72 & $\mathrm{~F}$ & W & $\begin{array}{l}\text { No } \\
(140 / 80)\end{array}$ & Nil & $\mathrm{PV}=1.76$ & RE normal & No drusen & $6 / 9$ & $6 / 9$ & - & \\
\hline & & & & & & & LE involved & $\begin{array}{l}\mathrm{Hg} \text { PED } \\
\text { (peripapillary) }\end{array}$ & $3 / 60$ & $3 / 60$ & Laser $(\times 3)$ & 3 \\
\hline \multirow[t]{2}{*}{5} & 71 & M & AC & $\begin{array}{l}\text { No } \\
(150 / 70)\end{array}$ & $\begin{array}{l}\text { MI, IHD, } \\
\text { asthma }\end{array}$ & $\uparrow P V=1.85$ & RE normal & No drusen & $6 / 6$ & $6 / 6$ & - & \\
\hline & & & & & & & LE involved & $\begin{array}{l}\text { Exudation, PED } \\
\text { (macular) }\end{array}$ & $6 / 9$ & $6 / 9$ & Laser & 6 \\
\hline
\end{tabular}

M, male; F, female; AC, Afro-Caribbean; W, White; MI, myocardial infarction; IHD, ischaemic heart disease; PV, plasma viscosity; Hg, haemorrhagic; PED, pigment epithelial detachment; $\mathrm{VH}$, vitreous haemorrhage.

report diverse demographic and clinical manifestations of this disease. Table 1 summarises the findings of the study with information on its associated systemic diseases and blood abnormality. Table 2 provides comparative information on the demographic characteristics and clinical manifestations of IPCV from the literature.

\section{Case 1}

A 58-year-old Afro-Caribbean man presented with a 1 week history of reduced visual acuity in the right eye. Ocular examination revealed a best corrected visual acuity of $6 / 36$ in the right eye and 6/5 in the left eye. There was no previous history of ocular problems or trauma. He was known to have syphilis but was otherwise well and was not taking any medication. Clinical examination revealed a haemorrhagic retinal pigment epithelial detachment and extensive subretinal haemorrhage over the superior arcade extending towards the right fovea. Fluorescein angiography demonstrated possible juxtapapillary choroidal neovascularisation which was ill-defined.

Three months later, the haemorrhage resolved and visual acuity returned to $6 / 6$. He developed a recurrence, a year later, with similar clinical findings at the same site in the same eye. There were additional exudation and localised orange-coloured polypoidal elevations within the subretinal haemorrhage. The clinical findings again resolved within 5 months leaving some degree of macular retinal pigment epithelial mottling with a vision of $6 / 12$.

In the following 2 years he experienced two more episodes of recurrent haemorrhagic retinal pigment epithelial detachments and neurosensory retinal detachments in the right eye, with spontaneous resolution. He developed a vitreous haemorrhage and massive subretinal haemorrhage which reduced the vision in his right eye to hand movements. Right pars plana vitrectomy was performed. Visual acuity did not improve due to macular scarring. His blood tests were normal and blood pressures were satisfactory at clinic visits.

\section{Case 2}

An 82-year-old Caucasian man was referred for assessment of a dense vitreous haemorrhage in his left eye. Ocular examination revealed a best corrected visual acuity of $6 / 60$ in his left eye. Fundoscopy of the right eye

Table 2. Demographic characteristics and clinical manifestations of IPCV from previous reports

\begin{tabular}{ll}
\hline Age: & Average $50-65$ years \\
Sex: & Females:males $=5: 1$ \\
Race: & Black:Asian:Whites $=4: 2: 1$ \\
Locations of polypoidal lesions: & Peripapillary, macular and mid-peripheral regions \\
Eye involvement: & Unilateral or bilateral \\
Clinical manifestations: & Recurrent haemorrhagic and exudative detachments of retinal and pigment epithelial layers \\
Other ocular features: & No drusen/lacquer cracks; no pathological myopia/ocular inflammation \\
Systemic feature: & Hypertensive (33-89\%) \\
\hline
\end{tabular}




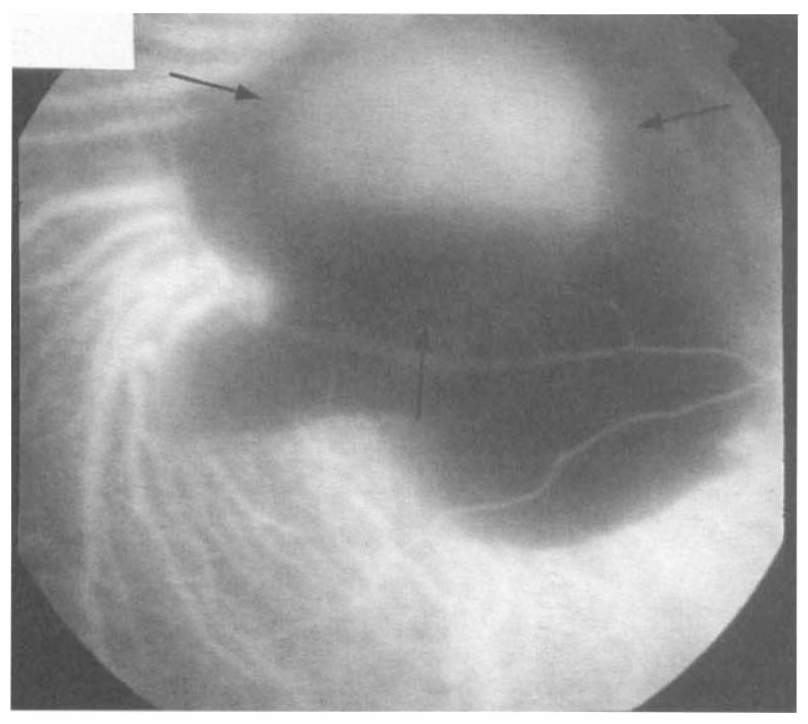

(a)

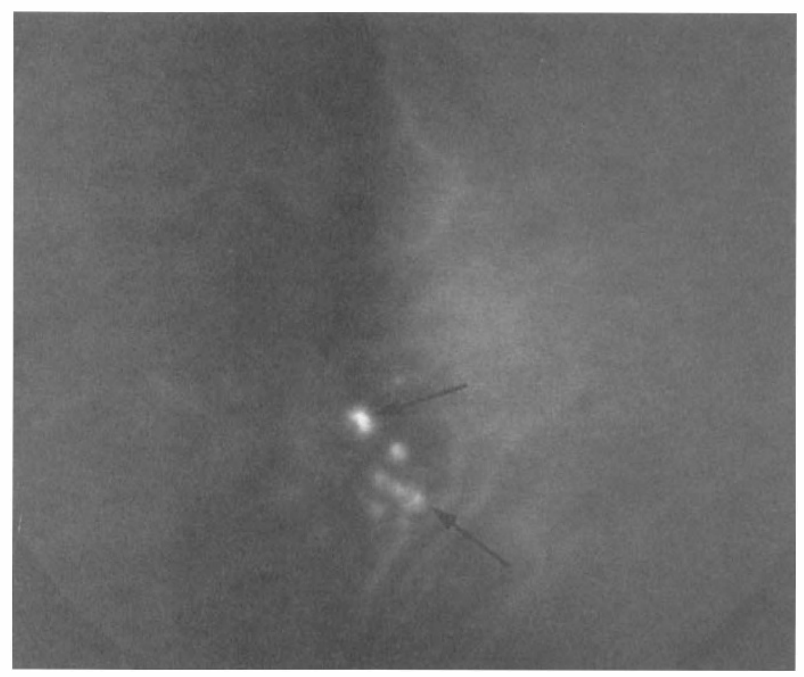

(c)

revealed a large asymptomatic haemorrhagic retinal pigment epithelial detachment (Fig. 1a) and neurosensory retinal detachments in the peripheral retina. His right vision was $6 / 12$ with no drusen over the macula. Indocyanine green angiography revealed the presence of polypoidal hyperfluorescent lesions at the margin of haemorrhagic pigment epithelial detachment (Fig. 1c), not as well demonstrated by fluorescein angiography (Fig. 1b).

Over the next 4 years he experienced recurrent episodes of multiple haemorrhagic retinal pigment epithelial detachment and vitreous haemorrhage at the peripheral retina which resolved spontaneously over 3-5 months, leaving extensive peripheral retinal pigment epithelial mottling.

This patient is not a known hypertensive but has had a history of multiple myocardial infarctions. He also has idiopathic thrombocytopenia but requires no treatment. He is on aspirin $75 \mathrm{mg}$ daily as strongly advised by his physician in view of his systemic cardiovascular problem.

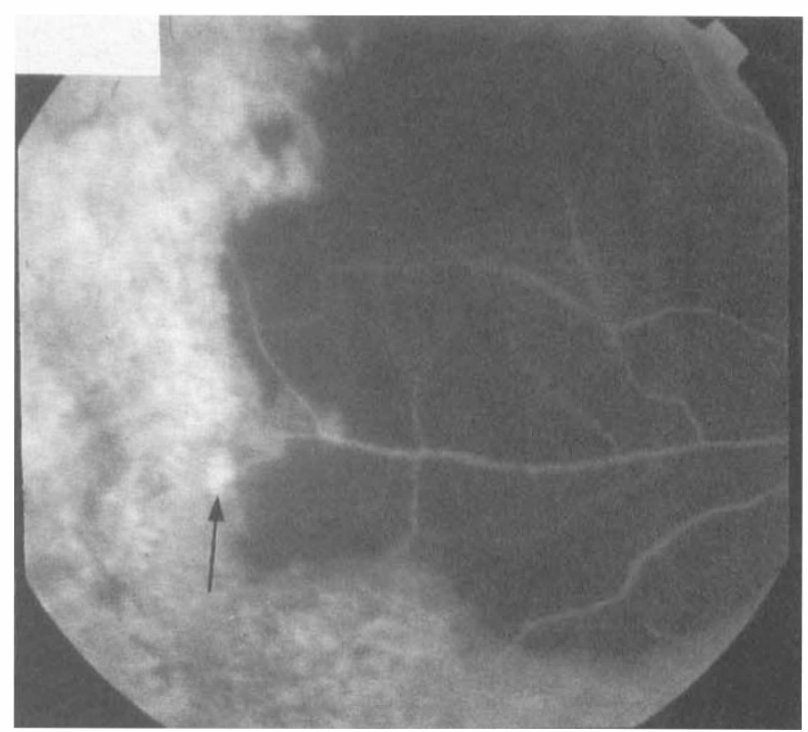

(b)

Fig. 1. Case 2. This patient has only peripheral IPCV with recurrent haemorrhagic retinal pigment epithelial detachments ( $a$, arrows) and subretinal haemorrhage. The polypoidal lesions are indistinct on fluorescein angiography $(b$, arrow) but better defined on indocyanine green angiography (c, arrows).

\section{Case 3}

A 63-year-old Afro-Caribbean woman was referred for assessment of a dense left vitreous haemorrhage. Ocular examination revealed a best corrected visual acuity of hand movements in her left eye with a dense central vitreous haemorrhage and subretinal haemorrhage over the macula. Although the right eye is asymptomatic with vision of $6 / 9$, a lobulated haemorrhagic retinal pigment epithelial detachment with surrounding subretinal haemorrhage in the superotemporal peripapillary region was found. Fluorescein and indocyanine green angiography revealed the presence of polypoidal hyperfluorescent lesions within this area of the right eye (Fig. 2a, b), but no view was possible in the left eye. The patient was observed at this stage as the haemorrhage was not threatening the fovea.

Six weeks later, there was extension of the subretinal haemorrhage towards the fovea and additional exudation formation (Fig. 2c). Repeat angiography showed persistent leakage from the polypoidal lesions. Argon green laser treatment was initiated to a few well-defined polypoidal lesions that posed a threat and 


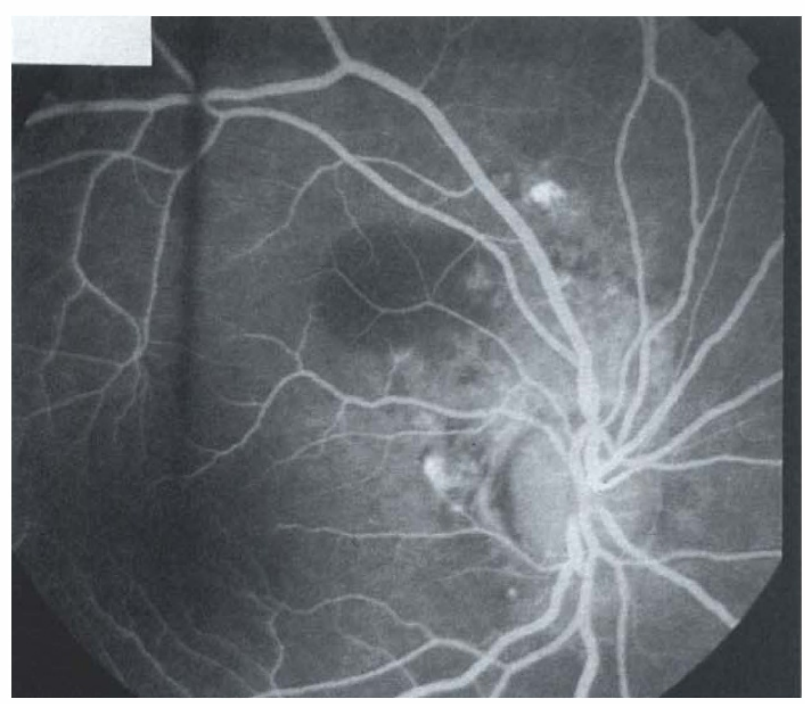

(a)

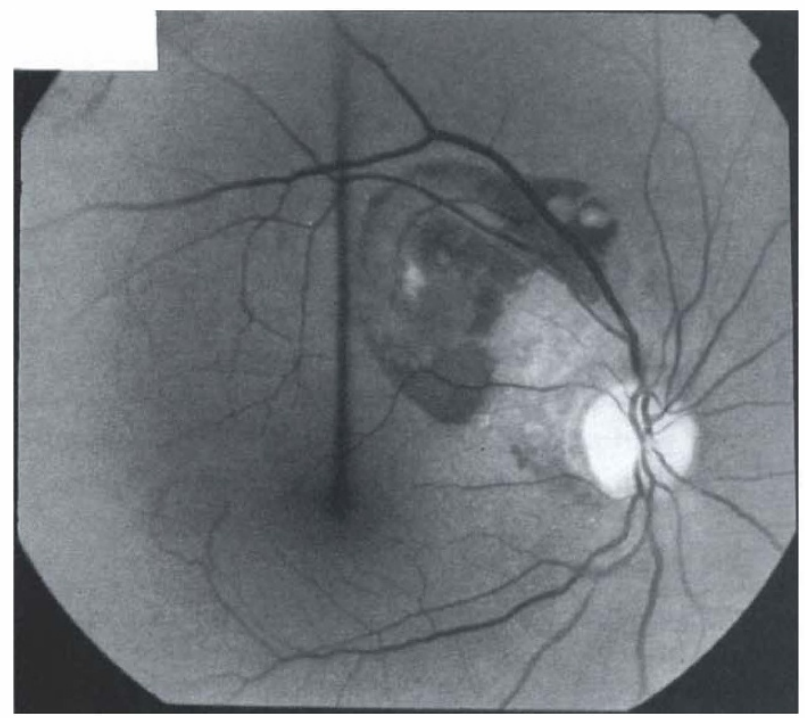

(c)

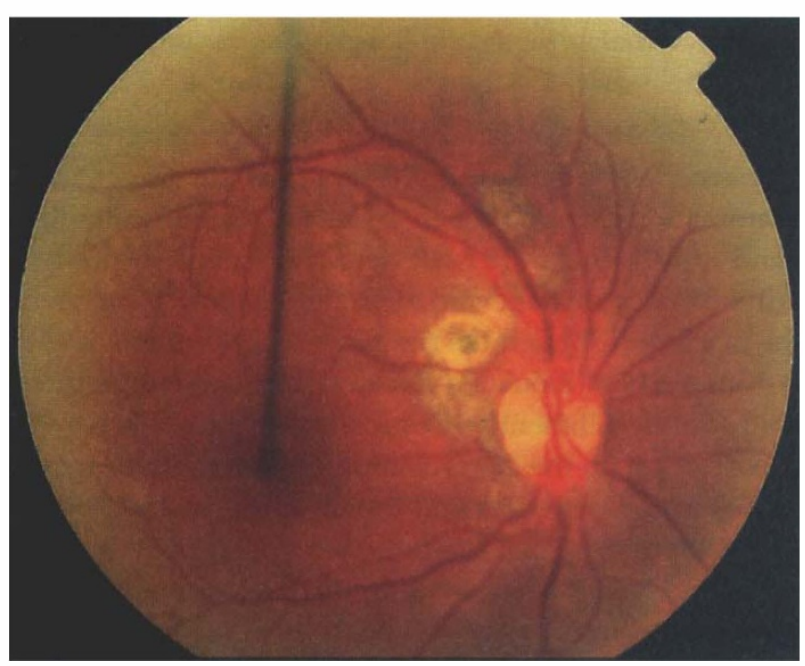

(e)

were nearest to the fovea. High-power laser was applied until the lesions turned white. Three consecutive applications were required to stop leakage from these lesions (Fig. 2d).

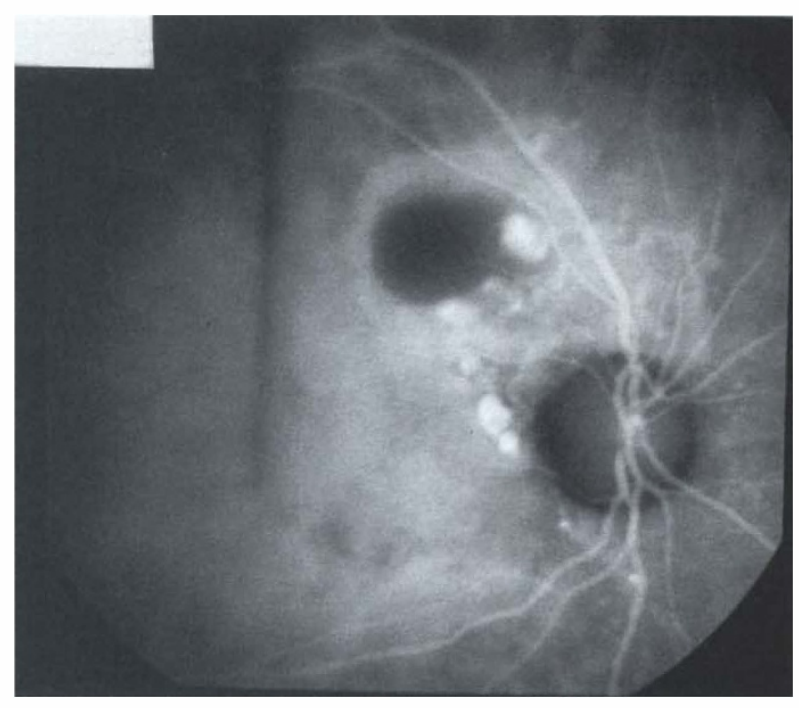

(b)

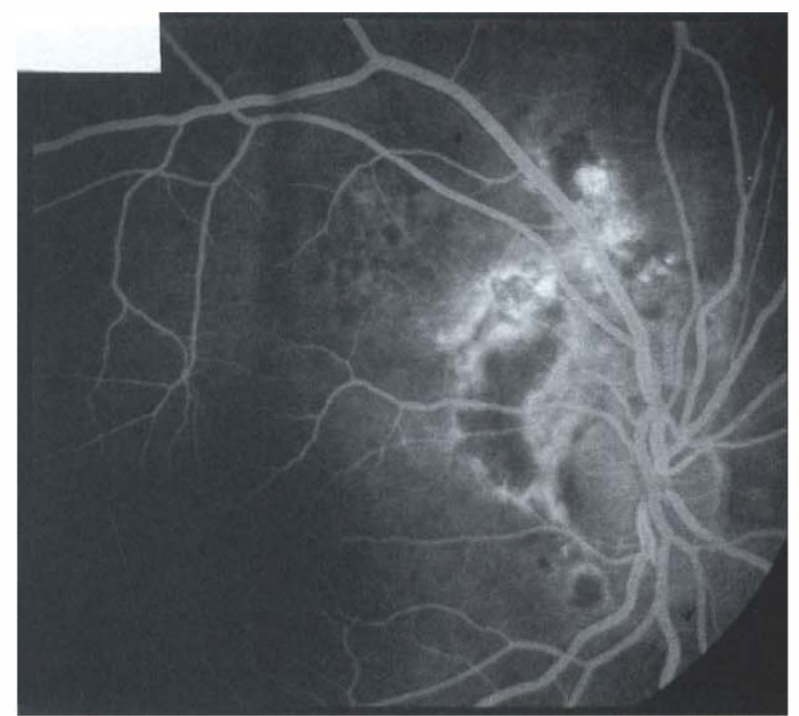

(d)

Fig. 2. Case 3. This patient presented with peripapillary haemorrhagic and exudative retinopathy resembling peripapillary choroidal neovascularisation secondary to age-related macular degeneration; fluorescein (a) and indocyanine green (b) angiography confirmed the presence of polypoidal choroidal lesions which were better defined by indocyanine green angiography. At the 6 week review there was clinical evidence of subretinal haemorrhage threatening the fovea (c). Given the history of recurrent vitreous haemorrhage in the other eye, laser photocoagulation was applied selectively to the polypoidal lesions within the superior arcade. Post-laser photocoagulation fluorescein angiography $(d)$ showed the ablated polypoidal lesions and resolution of the retinopathy with preservation of foveal function at 3 years follow-up (e).

The patient has maintained an excellent vision of $6 / 6$ in the right eye at 3 year follow-up (Fig. 2e) and has required no further laser treatment. Her left eye vision, however, is of counting fingers secondary to extensive 
macular scarring after the resolution of vitreous and submacular haemorrhage. Orange-coloured polypoidal lesions were also observed in the peripapillary region.

This patient is a known hypertensive and her blood pressure was uncontrolled with systemic medication at presentation. Haematological investigations had shown a high plasma viscosity, likely to be secondary to her hypertension.

\section{Case 4}

A 72-year-old woman was referred with a 4 year history of slow deterioration of her left vision but experienced further and rapid loss of vision in the previous month to $3 / 60$. Ocular examination had revealed large subretinal exudation involving the central macula and retinal pigment epithelial detachment superonasal to the fovea. Her right eye remains healthy with no evidence of drusen at the macula. Fluorescein angiography revealed diffuse leakage of hyperfluorescein over the left macular region, whereas indocyanine green angiography clearly outlined three polypoidal lesions at the superonasal macular region. Three applications of argon green laser photocoagulation were applied to all three lesions over a period of 2 months. Her left vision did not improve secondary to macular scarring but remained stable. She had no further episodes of recurrence following the laser treatment.

This patient had no significant past medical history and was on no systemic medication. She was normotensive and had normal blood tests.

\section{Case 5}

A 71-year-old Afro-Caribbean man was referred with a slight blurring of his left vision (6/9). He had previously had a course of laser treatment to his left macula elsewhere. Ocular examination revealed old heavy laser scar at the left superior macular region and there was some exudation surrounding the laser scar but not threatening the fovea. A large retinal pigment epithelial detachment was also noted inferonasal to the disc. Angiography revealed polypoidal lesions but with no active leakage on fluorescein angiography. His vision remained stable at a further 2 year follow-up without any further laser treatment.

This patient suffers from atrial fibrillation, ischaemic heart disease with cardiac failure and asthma. His oral medication includes aspirin $75 \mathrm{mg}$ per day but not warfarin. His blood pressures were normal at clinic visits. Blood investigations revealed a high plasma viscosity.

\section{Discussion}

IPCV was first described in the early 1980s, with a few series reported over the decades described with different names such as 'multiple recurrent serosanguineous retinal pigment epithelial detachments in black women ${ }^{4}$ and 'posterior uveal bleeding syndrome', ${ }^{5}$ based on its clinical manifestations. The term IPCV was more appropriately applied ${ }^{1}$ for its unknown pathogenesis, clearly different from age-related maculopathy. The introduction of indocyanine green angiography has enabled it to be demonstrated that the primary abnormality of this disease involves the choroidal circulation. The characteristic lesions are an abnormal network of inner choroidal vascular aneurysmal outward projections, visible clinically as reddish-orange polypoidal structures. ${ }^{2}$ These lesions have been described predominantly over the peripapillary and macular regions by others. However, a mid-peripheral lesion giving rise to subretinal haemorrhage has also been reported recently. ${ }^{6}$ We report peripheral retina (anterior to equator) involvement of two eyes of the same patient in this series with frequent vitreous haemorrhage. Five year follow-up on this patient has shown that there was no potential extension or proliferation of the 'abnormal polypoidal network' towards the macula but recurrent vitreous haemorrhage did appear to be the main problem.

Other demographic characteristics of the patients and clinical manifestations have been reasonably consistent with previous reports of this entity ${ }^{1,3,7}$ (Tables 1, 2). However, only one patient from our series suffered from hypertension for which they were on systemic medication. Without any histopathological information, the pathogenesis of IPCV is difficult to determine. However, it is reasonable to assume that the polypoidal choroidal vascular projections of IPCV may be the hypertensive choroidal vascular equivalent of hypertensive retinal vasculopathy associated with retinal arterial macroaneurysm as reported by Ross et al. ${ }^{7}$ The peripapillary predominance of IPCV analogous to retinal vascular arteriovenous crossings, might be explained by the increased intravascular stress and thrombotic predisposition observed in these areas, further aggravated by hypertension. ${ }^{8,9}$ Perhaps the closest histopathological and angiographic description of these polypoidal lesions is from one study using optical coherence tomography. ${ }^{10}$ This reported that the polypoidal structures originated from the inner choroidal layer, protruding anteriorly through the damaged overlying Bruch's membrane and retinal pigment epithelium, leading to serosanguineous detachment of the retina. ${ }^{10}$

Even though the angiographic features of IPCV are clearly different from age-related choroidal neovascularisation, its clinical outcome is similar, leading to haemorrhagic and exudative retinopathy causing severe visual disability, especially when the macula is involved. Three patients in this series had actively leaking polypoidal lesions. Laser photocoagulation was performed in 2 patients when there was evidence of progressive exudative or haemorrhagic macula involvement. Only those polypoidal lesions that were near and threatened the fovea received laser photocoagulation, with parameters similar to those applied to age-related choroidal neovascularisation. However, at least three sessions of laser were required to 
achieve total ablation. Patients who received laser treatment in this series maintained their initial visual acuity, with no evidence of recurrence after 3-6 years of follow-up. The two patients who had not received laser photocoagulation experienced further loss of vision secondary to recurrent dense vitreous haemorrhage. There was no standard treatment protocol available from the literature for patients suffering from IPCV. We have taken a rational approach in these patients and it is reasonable to suggest that laser photocoagulation may prevent severe visual loss if performed early. The polypoidal lesions are often multiple, so we suggest that selective laser treatment on lesions within the maculae that threaten the fovea is more appropriate.

In this series, hypertension was present in only 1 patient. One other interesting systemic association is blood abnormality: raised plasma viscosity level and thrombocytopenia. Several epidemiological studies have indicated strong and positive associations between plasma viscosity (which is largely determined by fibrinogen) and other cardiovascular risk factors such as smoking, hypertension and cholesterol. ${ }^{11,12}$ Increased plasma viscosity leads to impairment of the microcirculation, induces high coagulability and therefore increased fibrin deposition which in turn leads to the development of atherosclerotic disease. These atherosclerotic changes and, additionally, hypertensive stresses may cause choroidal vascular histological damage with hyaline degeneration, adventitial thickening, and subsequent tortuosity with focal arterial constrictions and dilatations, predisposing to thrombus formation. ${ }^{8,9,13}$ The presence of coexisting systemic cardiovascular disease and blood abnormality may predispose to frequent haemorrhagic tendency in IPCV.

IPCV remains an interesting differential diagnosis in patients suffering from recurrent haemorrhagic and exudative maculopathy. The clinical spectrum of IPCV is wider than previously documented. The polypoidal lesions could also be a peripheral disease, as described in one of our patients. It is suggested in the literature that the nature of this disease is benign. ${ }^{1,8}$ The clinical course of our patients shows that they do lose central vision from this disease in the untreated eyes. Therefore, the natural history of this disease may not be as benign as previously thought. All three patients responded well to laser photocoagulation, with resolution of the exudative manifestations and stabilisation of their central visual acuity. The availability of indocyanine green angiography has allowed increased recognition of these cases and thus a different clinical approach. A prospective controlled study would provide more valid and appropriate guidelines in the treatment and management of patients in this special disease entity.

\section{References}

1. Yannuzzi LA, Sorenso J, Spaide RF, Lipson B. Idiopathic polypoidal choroidal vasculopathy. Retina 1990;10:1-8.

2. Spaide RF, Yannuzzi LA, Slakter JS, Sorenso JA, Orlock DA. Indocyanine green videoangiography of idiopathic polypoidal choroidal vasculopathy. Retina 1995;15:100-10.

3. Yannuzzi LA, Ciardella A, Spaide RF, Rabb M, Freund B, Orlock DA. The expanding clinical spectrum of idiopathic polypoidal choroidal vasculopathy. Arch Ophthalmol 1997;115:478-85

4. Stern RM, Zakov N, Zegarra H, Gutman FA. Multiple recurrent serosanguineous retinal pigment epithelial detachments in black women. Am J Ophthalmol 1985;100:560-9.

5. Kleiner RC, Brucker AJ, Johnston RL. The posterior uveal bleeding syndrome. Retina 1990;10:9-17.

6. Yannuzzi LA, Nogueira FB, Spaide RF, Guyer DR, Orlock $\mathrm{DA}$, Colombero D, et al. Idiopathic polypoidal choroidal vasculopathy: a peripheral lesion [letter]. Arch Ophthalmol 1998;116:382-3.

7. Ross RD, Gitter KA, Cohen G, Schomaker KS. Idiopathic polypoidal choroidal vasculopathy associated with retinal macroaneurysm and hypertensive retinopathy. Retina 1996;16:105-11.

8. Ring HG, Fujino T. Observations on the anatomy and pathology of the choroidal vasculature. Arch Ophthalmol 1967;78:431-4.

9. Tso MOM, Jampol LM. Pathophysiology of hypertensive retinopathy. Ophthalmology 1982;93:60-73.

10. Iijima $H$, Imai $M$, Gohdo $T$, Tsukahara S. Optical coherence tomography of idiopathic polypoidal choroidal vasculopathy. Am J Ophthalmol 1999;127:301-5.

11. Yarnell JWG, Baker IA, Sweetnam PM, et al. Fibrinogen, viscosity and white blood cell count are major risk factors for ischaemic heart disease. The Caerphilly and Speedwell Collaboration Heart Disease Studies. Circulation 1991;83:836-44.

12. Moller L, Kristensen TS. Plasma fibrinogen and ischaemic heart disease risk factors. Arterioscleros Thromb 1991;11:344-50.

13. Friedman E, Smith TR, Kuwabara T, et al. Choroidal vascular patterns in hypertension. Arch Ophthalmol 1985;60:235-91. 